\title{
AVALIAÇÃO ERGONÔMICA DO ATELIÊ 4 DO CURSO DE ARQUITETURA E URBANISMO DA UNIVERSIDADE FEDERAL DE PERNAMBUCO
}

\author{
LIMA, Jéssyca Valéria de (1); \\ SILVA, Jônatas Souza Medeiros da (2); \\ AZERÊDO, Jaucele (3) \\ (1) UFPE, Graduanda em Arquitetura e Urbanismo \\ e-mail: jessycadelima6@gmail.com \\ (2) UFPE, Graduando em arquitetura e Urbanismo \\ e-mail: jona.medeiros@gmail.com \\ (3) UFPE, Professora em Arquitetura e Urbanismo \\ e-mail: jaucele azeredo@hotmail.com
}

\begin{abstract}
RESUMO
A ergonomia é o estudo da relação homem-ambiente, que ao aplicar técnicas para adaptação do espaço, busca proporcionar conforto, saúde e bem-estar aos usuários. Nesse contexto, este artigo resulta da aplicação de parte da metodologia MEAC, proposta por Villarouco, em uma sala de aula localizada no Centro de Artes e Comunicação na Universidade Federal de Pernambuco - UFPE, Campus Recife. Teve como objetivo geral realizar uma avaliação ergonômica no ateliê 4, visando observar a interação dos usuários com o espaço, a partir de aspectos psicológicos e organizacionais. Como objetivos específicos, buscou verificar o nível de satisfação dos usuários e observar condicionantes passíveis de estudo e de futuras intervenções no ambiente estudado.
\end{abstract}

Palavras chave: Metodologia MEAC; Ergonomia; Ambiente Construído.

\begin{abstract}
Ergonomics is the study of the man-environment relationship, which, when applying techniques for adapting space, seeks to provide comfort, health and well-being to users. In this context, this article results from the application of part of the MEAC methodology, proposed by Villarouco, in a classroom located at the Center of Arts and Communication at the Federal University of Pernambuco - UFPE, Campus Recife. The general objective was to carry out an ergonomic evaluation in atelier 4, in order to observe the users' interaction with space, based on psychological and organizational aspects. As specific objectives, it sought to verify the satisfaction level of users and to observe conditions that could be studied and future interventions in the studied environment.
\end{abstract}

Keywords: Methodology MEAC; Ergonomics; Built Environment. 


\section{(x) $^{\text {enec }}$}

\section{A ERGONOMIA COMO FATOR DE BUSCA PELA QUALIDADE DO ESPAÇO}

A visão do homem, canalizada no espaço, compreende, de maneira coerente, a sua composição, respeitosamente voltada à dimensão humana. A ergonomia considera que os ambientes, de uma maneira geral, estão diretamente relacionados ao homem, seja por meio da necessidade de adaptação do espaço para com o corpo, seja em função do seu comportamento perante o lugar. Assim, percebe-se a necessidade de integração do usuário em relação ao seu espaço de convívio.

É destacado, a partir de Moraes (2004, p.69), que além da relação homem-ambiente, deve ser considerado como fator crucial a relação homem-objeto, onde este entra em confronto direto na questão de apropriação, seja através do mobiliário ou de outros equipamentos que compõem o espaço e estejam introduzidos no cotidiano dos usuários.

A compreensão bioclimática do lugar e as ações antrópicas desenvolvidas no espaço fazem com que haja alterações no comportamento do espaço ao ser apropriado pelo usuário, como também a necessidade de sua adequação, seja por questões da antropometria organização espacial em relação ao usuário - ou até mesmo de acessibilidade necessidade de um desenho universal para usufruto do espaço de modo equitativo, defendido por Carletto e Cambiaghi (2008, p.12).

Percebe-se que os desdobramentos obtidos pela análise do espaço - sejam respostas de formulários, medições das variáveis relativas ao conforto ambiental, análise quanto à disposição e layout do ambiente - não são sempre suficientes para a compreensão do espaço. Desse modo, também devem ser levados em consideração outros aspectos igualmente importantes: psicológicos, culturais e sociais.

Desse modo, apresentou-se como objetivo deste artigo, realizar uma avaliação ergonômica no ateliê 4 visando observar a interação dos usuários com o espaço, a partir de aspectos psicológicos e organizacionais. $O$ ateliê 4 é uma das salas de aula prática do curso de Arquitetura e Urbanismo, do Centro de Artes e Comunicação - CAC, da Universidade Federal de Pernambuco - UFPE.

A fim de compreender as características do ambiente em foco na pesquisa, tanto suas problemáticas e potencialidades, quanto o funcionamento das dinâmicas sociais, faz levar em consideração a necessidade de avaliar questões relativas à: antropometria, conforto ambiental, acessibilidade, dentre outros fatores. Para assim, sugerir possíveis soluções que busquem a melhoria do espaço estudado, quando se fizer necessário.

Com isso, foi visado o planejamento desta avaliação como ponto inicial desta pesquisa. Uma organização metodológica foi utilizada, em busca de uma análise ergonômica precisa do espaço desejado, para assim, chegar a soluções que pudessem apontar diretrizes de melhorias tanto para o local quanto, e principalmente, aos usuários que irão se apropriar dele. Neste estudo, consideraram-se quatro etapas cruciais para o entendimento da situação existente na sala de aula, baseadas em parte da Metodologia Ergonômica para o Ambiente Construído - MEAC desenvolvida por Villarouco (2008), a saber:

- Análise Geral do Ambiente (conformação espacial);

- Identificação dos parâmetros envolvidos ao conforto ambiental (levantamentos de dados físicos, dimensões de mobiliários, medições técnicas etc.);

- Análise da Percepção do Usuário (aplicação de formulários, obtendo a opinião dos usuários sobre o ambiente);

- Diagnóstico Ergonômico do Ambiente (avaliação técnica em relação aos dados obtidos pelos formulários aplicados e através dos dados a partir dos levantamentos e medições microclimáticas); 


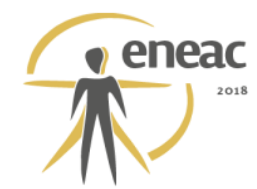

Desse modo, foi pretendido chegar a um estudo da situação existente da sala de aula, com o intuito de propor diretrizes para sua melhoria quanto ao conforto e à sensação de bemestar dos estudantes e professores.

\section{A AVALIAÇÃO ERGONÔMICA COMO OBJETO DE COMPREENSÃO DO ESPAÇO}

Compreender o espaço faz parte do processo inicial de uma avaliação ergonômica. O Ateliê de Arquitetura e Urbanismo 4, ambiente estudado nesta pesquisa, está localizado no Centro de Artes e Comunicação - CAC/UFPE, prédio de estilo arquitetônico moderno, de linhagem brutalista e trabalhado com o sistema modular interligado ao partido orgânico-funcional. Seu espaço é dimensionado neste conjunto modular, sua conformação espacial é dividida em três seções para atender à demanda educacional necessária para as aulas do curso. São elas: espaço teórico, espaço prático e depósito (figura 1).

Figura 1 - Zoneamento do ateliê, em planta baixa.
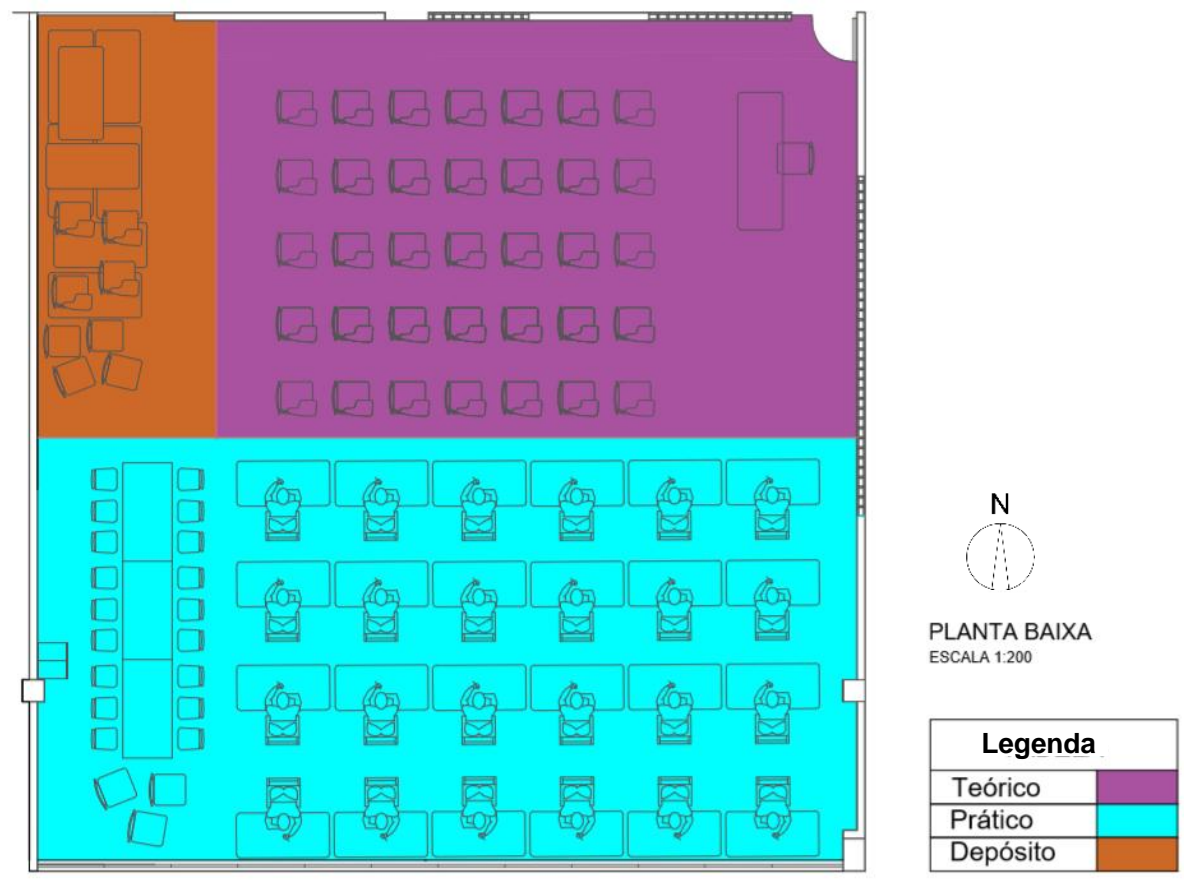

Fonte - Arquivo pessoal, 2015.

Este zoneamento, como também, a espacialização dos objetos encontrados no ambiente em estudo, facilitam a análise deste ambiente, onde correlacionam-se com os fatores ambientais que gerenciam a dinâmica do espaço. Para isto, foi desenvolvido um estudo sistêmico relacionado ao Conforto Ambiental acerca de fatores microclimáticos e antrópicos voltados à análise direta com o bem-estar do usuário, além da avaliação de aspectos relativos à sua acessibilidade.

Esta abordagem é defendida por Villarouco e Mont'Alvão (2011 p. 31), lembrando-se, assim, que "faz-se necessário uma abordagem sistêmica quando se trata de avaliar o ambiente da ótica da ergonomia." (ibid. p. 30). 


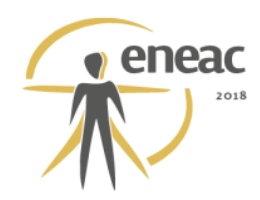

Foi escolhido, pelos avaliadores, o horário de maior utilização da sala de aula - no caso, o período vespertino - entre as $13 \mathrm{~h}$ e $17 \mathrm{~h}$. Durante o decorrer de uma semana letiva realizaram-se as etapas de avaliação do ambiente, traçadas a partir de um cronograma organizado e aplicado por cinco discentes/pesquisadores envolvidos - cada qual responsável por etapas específicas desse cronograma, para assim, otimizar a coleta de dados -, supervisionados por duas docentes/pesquisadoras responsáveis pelas atividades desenvolvidas.

Foram utilizados os seguintes programas computacionais durante a execução dessa etapa da pesquisa: Microsoft Excel, para criação e análise de tabelas com os dados registrados; AutoCAD, para espacialização em figuras dos resultados obtidos e análise da situação do ambiente, de forma gráfica; o programa Analisys SOL-AR, para análise dos fatores microclimáticos e sua inserção no espaço estudado.

\subsection{Avaliação dos Fatores Microclimáticos}

A maneira como a direção e a velocidade do vento, a temperatura do ar, o nível de luminosidade e a presença de ruído se apresentam no ambiente interfere diretamente nas atividades realizadas, já que se encontra paralelamente ligada à situação humana, como citado por Villarouco (2008).

Durante a coleta dos dados microclimáticos foram utilizados os seguintes instrumentos disponibilizados pelo Laboratório de Conforto Ambiental (Lacam), vinculado ao Departamento de Arquitetura e Urbanismo/UFPE: Termohigrômetro, marca "Instrutherm", modelo "HT-300", para medições das variáveis temperatura do $\operatorname{ar}\left({ }^{\circ} \mathrm{C}\right)$ e umidade relativa do ar (\%); Luxímetro, marca "Acso", modelo "AK-309", visando à medição do nível de luminosidade (lux); Termoanemômetro, marca "Instrutherm", modelo "TAD-500", para a medição da velocidade do vento $(\mathrm{m} / \mathrm{s})$; e Decibelímetro (Sonômetro), marca "Minipa", modelo "MSL-1325A", paras as medições relativas ao nível de ruído do ambiente (dB).

Essas medições foram realizadas durante o turno vespertino, período de maior constância em relação à utilização do espaço, principalmente entre as $14 \mathrm{~h}$ e $15 \mathrm{~h}$. Houve a escolha de cinco pontos de medições, sendo indicada a eleição de pontos extremos - um em cada vértice da sala de aula -, além do ponto central do ambiente; obtiveram-se, assim, informações mais precisas quanto aos resultados, o que colaborou com a melhor compreensão do espaço (figura 2).

As medições foram realizadas pelos discentes responsáveis pelo desenvolvimento da pesquisa, cada qual responsável por um dos equipamentos, logo, uma das variáveis microclimáticas a serem analisadas. Durante a medição, houve os alunos que auxiliavam na avaliação e compreensão das informações obtidas, a partir de notas, registros fotográficos, espacialização das medidas e discussões sobre casos e consequências relacionadas a cada variável, fosse ela térmica, lumínica ou acústica. 


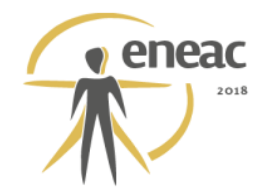

Figura 2 - Espacialização dos pontos de medição.

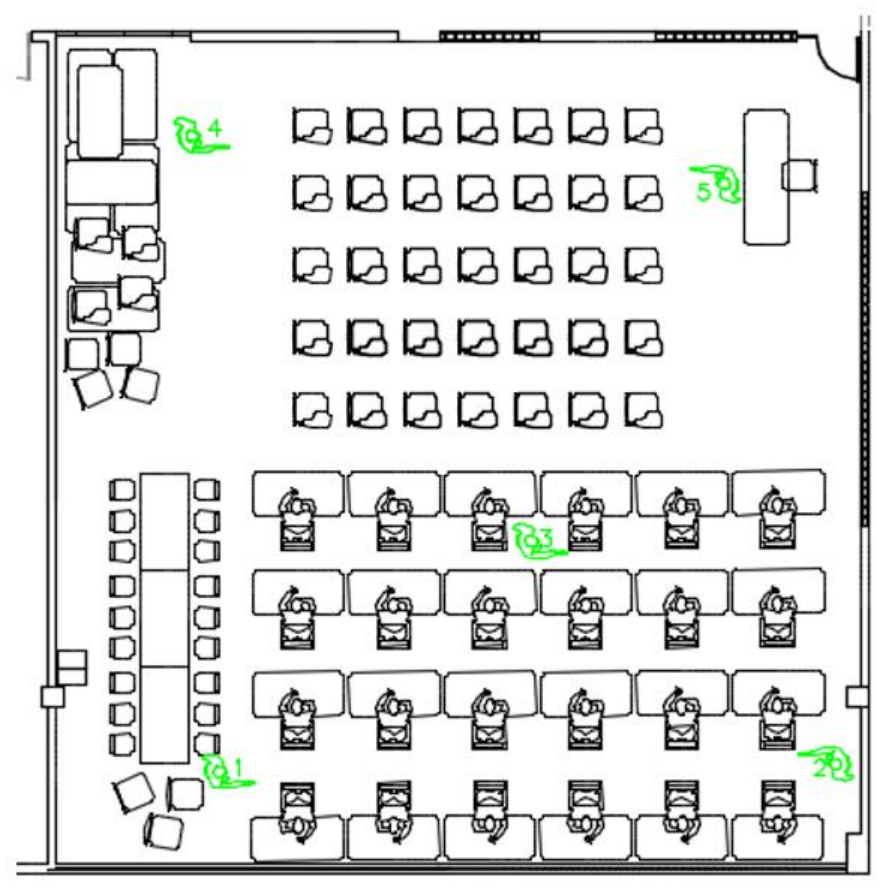

Fonte - Arquivo pessoal, 2015.

Um dos primeiros elementos analisados no ambiente escolhido foi a sensação de conforto térmico. No processo das medições técnicas para a variável climática "temperatura", percebeu-se uma estagnação geral no ateliê, com altas temperaturas, acima da zona de conforto térmico, independentemente do ponto de medição local, de fatores naturais e de equipamentos encontrados em seu entorno.

Ao analisar a tabela 1, elaborada a partir dos resultados das medições - realizadas durante um período de 5 (cinco) minutos em cada ponto demarcado, onde foram destacados os valores mais altos e o valor médio registrado -, percebe-se que houve uma variação igual a $1,1^{\circ} \mathrm{C}$, entre os valores extremos (menor valor em relação ao maior valor da medição); ao espacializar estas informações, chegou-se ao mapa térmico (figuras $3 a$ e $3 b$ ) que melhora a compreensão das altas temperaturas no ambiente - com variação entre $30.1^{\circ} \mathrm{C}$ e $31.2^{\circ} \mathrm{C}$.

Pode-se perceber, facilmente, que próximo à janela (setor sudeste) há variação de temperatura. A oeste, estão as temperaturas mais amenas, já a leste, as mais elevadas; isto por causa de uma barreira existente, como também, pela falta de equipamentos de ventilação nesta área, e os existentes não se encontravam funcionando. Ao norte, percebeuse a presença de ventilação natural, vinda de nordeste, por meio das portas e dos cobogós, como também, os equipamentos de ventilação artificial que auxiliam com a amenização da temperatura.

De acordo com a NR17, em locais de trabalho onde são executadas atividades que exijam solicitação intelectual e atenção constantes, dentre os quais são citadas salas de desenvolvimento ou análise de projetos, são recomendados índices de temperatura efetiva entre 20 a $23^{\circ} \mathrm{C}$. Reitera-se que, há que se considerar a adequação desses valores para o clima da cidade de Recife. Ratifica-se a grande necessidade de uma intervenção no ambiente Ateliê 4, sob o viés térmico, visando à sensação de conforto dos usuários. 
Tabela 1 - Resultados das medições relacionadas ao conforto ambiental, no ateliê 4.

\begin{tabular}{|c|c|c|c|c|c|}
\hline \multirow[b]{2}{*}{ MEDIÇÃO } & \multirow[b]{2}{*}{ TEMPERATURA } & \multicolumn{4}{|c|}{ MEDIÇÕES RELACIONADAS AO CONFORTO AMBIENTAL } \\
\hline & & LUX & UMIDADE RELATIVA & VELOCIDADE DO VENTO* & PRESENÇA DE RUÍDO* \\
\hline PONTO 1 & & 463lux & & & \\
\hline PICO & $30.8^{\circ} \mathrm{C}$ & & $55.2 \%$ & $0.9 \mathrm{~m} / \mathrm{s}$ & $66.2 \mathrm{db}$ \\
\hline MÉDIA & $30.1^{\circ} \mathrm{C}$ & & $54.1 \%$ & $0.5 \mathrm{~m} / \mathrm{s}$ & $64.3 \mathrm{db}$ \\
\hline PONTO 2 & & 389lux & & & \\
\hline PICO & $31.2^{\circ} \mathrm{C}$ & & $54.9 \%$ & $0.3 \mathrm{~m} / \mathrm{s}$ & $69.0 \mathrm{db}$ \\
\hline MÉDIA & $31.0^{\circ} \mathrm{C}$ & & $54.8 \%$ & $0.2 \mathrm{~m} / \mathrm{s}$ & $64.2 \mathrm{db}$ \\
\hline PONTO 3 & & 042lux & & & \\
\hline PICO & $31.1^{\circ} \mathrm{C}$ & & $56.6 \%$ & $0.2 \mathrm{~m} / \mathrm{s}$ & $78.5 \mathrm{db}$ \\
\hline MÉDIA & $30.8^{\circ} \mathrm{C}$ & & $56.1 \%$ & $0.1 \mathrm{~m} / \mathrm{s}$ & $63.5 \mathrm{db}$ \\
\hline PONTO 4 & & 015lux & & & \\
\hline PICO & $31.0^{\circ} \mathrm{C}$ & & $57.8 \%$ & $0.6 \mathrm{~m} / \mathrm{s}$ & $70.5 \mathrm{db}$ \\
\hline MÉDIA & $30.8^{\circ} \mathrm{C}$ & & $57.4 \%$ & $0.5 \mathrm{~m} / \mathrm{s}$ & $67.0 \mathrm{db}$ \\
\hline PONTO 5 & & 016lux & & & \\
\hline PICO & $30.9^{\circ} \mathrm{C}$ & & $58.0 \%$ & $0.5 \mathrm{~m} / \mathrm{s}$ & $76.8 \mathrm{db}$ \\
\hline MÉDIA & $30.8^{\circ} \mathrm{C}$ & & $57.5 \%$ & $0.3 \mathrm{~m} / \mathrm{s}$ & $72.0 \mathrm{db}$ \\
\hline
\end{tabular}

Fonte - Arquivo pessoal, 2015.

Figura 3 - Espacialização climática - medição de temperatura do ar, no ateliê 4. Planta baixa mobiliada (3a) e equipamentos de ventilação e de iluminação (3b).

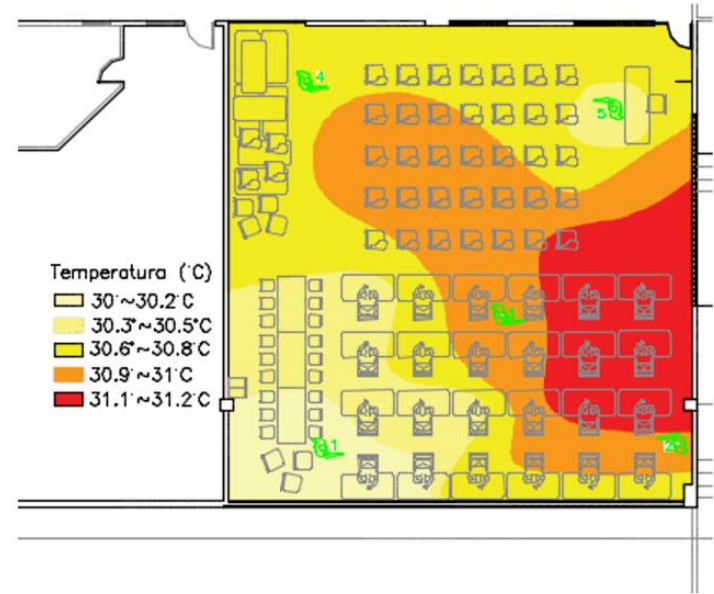

(a)

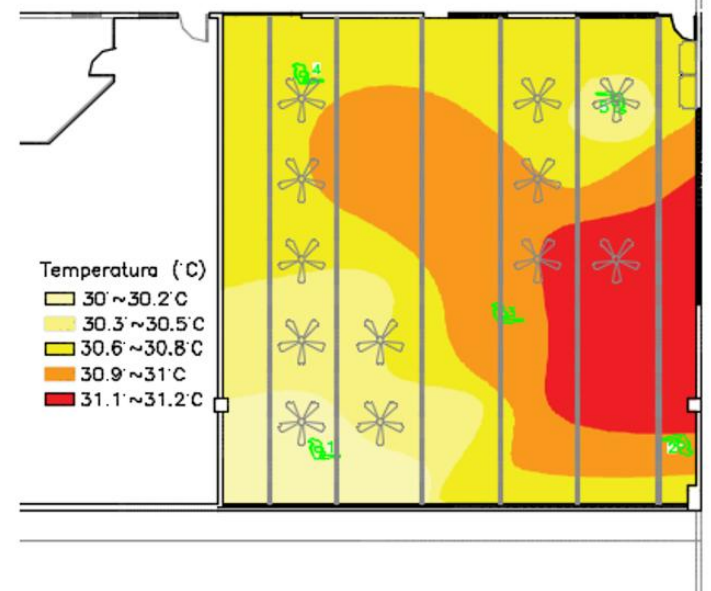

(b)

Fonte - Arquivo Pessoal, 2015.

Através do mesmo instrumento que mediu a temperatura do ar, termohigrômetro, foi aferida a umidade relativa do ar. Com as medições obtidas - com a mesma conformação do fator anterior -, percebeu-se que não houve uma grande variação, não ultrapassando $3 \%$. Ao transformar os dados da tabela $1 \mathrm{em}$ um figura de espacialização de umidade (figura 4), percebeu-se que quanto mais longe das áreas que têm contato direto com o sol, onde as temperaturas eram mais altas, mais elevados eram os valores da umidade, comprovando a relação de inversabilidade entre as variáveis temperatura e umidade relativa do ar. 


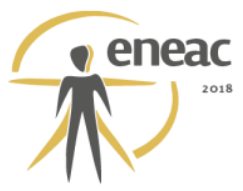

Porém, também foi visto que grande parte dos locais onde não se tem probabilidade de contato direto com o sol, e também apresentando valores de umidade elevados, se encontrava ocupado com entulhos. Assim, deve-se ter maior precaução, pois há a possibilidade da infestação de xilófagos, manchas, fungos e bactérias; além de ocupar espaços que seriam mais confortáveis para os usuários. Mesmo com os valores apresentados nesta análise, de acordo com a NR17, o ambiente está com umidade adequada, acima de $40 \%$.

Figura 4 - Espacialização climática - medição de umidade relativa do ar, no ateliê 4.

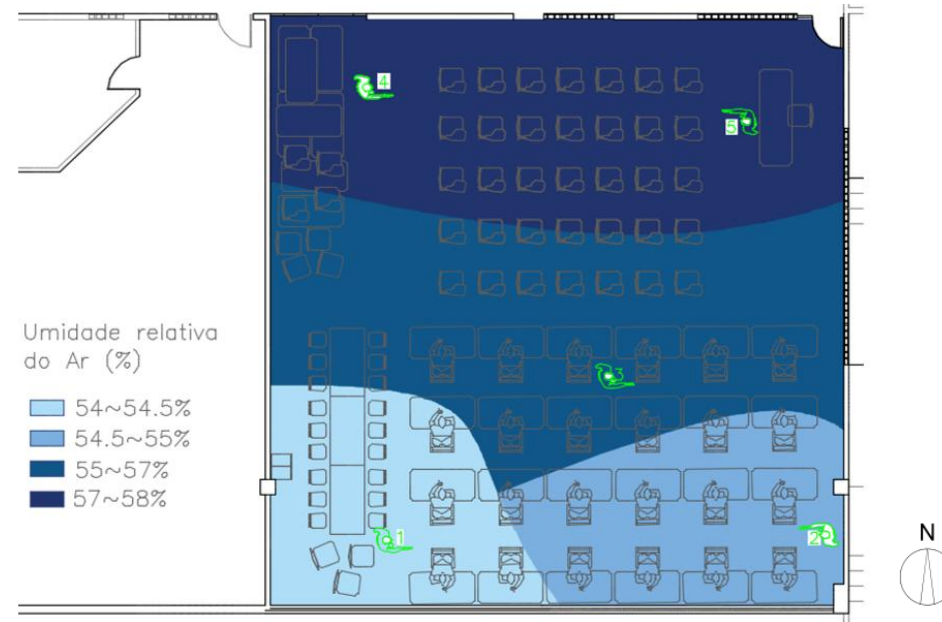

Fonte - Arquivo pessoal, 2015.

Para complementar a análise do conforto térmico do ambiente, houve a necessidade de se observar o comportamento da ventilação do ar - velocidade e direção do vento que penetra o ambiente. Percebe-se, ao analisar as tabelas $2 \mathrm{a}$ e $2 \mathrm{~b}$ - confeccionadas a partir das cinco medições intercaladas, uma em cada minuto, onde foram destacados o valor denominado "pico" e o valor médio, para cada ponto de medição -, que a velocidade predominante variou de 0,1 a $0,5 \mathrm{~m} / \mathrm{s}$, chegando a alcançar o valor de $0,9 \mathrm{~m} / \mathrm{s}$.

Tabela 2 - Resultados das medições - velocidade do vento $(\mathrm{m} / \mathrm{s})(\mathrm{a})$ e ruído (dB) (b).

\begin{tabular}{lccccc}
\hline & MINUTO 1 & MINUTO 2 & MINUTO 3 & MINUTO 4 & MINUTO 5 \\
\hline PONTO 1 & $0.8 \mathrm{~m} / \mathrm{s}$ & $0.5 \mathrm{~m} / \mathrm{s}$ & $0.9 \mathrm{~m} / \mathrm{s}$ & $0.2 \mathrm{~m} / \mathrm{s}$ & $0.3 \mathrm{~m} / \mathrm{s}$ \\
\hline PONTO 2 & $0.2 \mathrm{~m} / \mathrm{s}$ & $0.1 \mathrm{~m} / \mathrm{s}$ & $0.1 \mathrm{~m} / \mathrm{s}$ & $0.2 \mathrm{~m} / \mathrm{s}$ & $0.3 \mathrm{~m} / \mathrm{s}$ \\
\hline PONTO 3 & $0.2 \mathrm{~m} / \mathrm{s}$ & $0.1 \mathrm{~m} / \mathrm{s}$ & $0.1 \mathrm{~m} / \mathrm{s}$ & $0.1 \mathrm{~m} / \mathrm{s}$ & $0.1 \mathrm{~m} / \mathrm{s}$ \\
\hline PONTO 4 & $0.5 \mathrm{~m} / \mathrm{s}$ & $0.4 \mathrm{~m} / \mathrm{s}$ & $0.6 \mathrm{~m} / \mathrm{s}$ & $0.4 \mathrm{~m} / \mathrm{s}$ & $0.4 \mathrm{~m} / \mathrm{s}$ \\
\hline PONTO 5 & $0.3 \mathrm{~m} / \mathrm{s}$ & $0.5 \mathrm{~m} / \mathrm{s}$ & $0.4 \mathrm{~m} / \mathrm{s}$ & $0.1 \mathrm{~m} / \mathrm{s}$ & $0.1 \mathrm{~m} / \mathrm{s}$ \\
\hline
\end{tabular}

(a)

\begin{tabular}{|lccccc|}
\hline & MINUTO 1 & MINUTO 2 & MINUTO 3 & MINUTO 4 & MINUTO 5 \\
\hline PONTO 1 & $63.4 \mathrm{db}$ & $64.1 \mathrm{db}$ & $65.2 \mathrm{db}$ & $64.3 \mathrm{db}$ & $64.5 \mathrm{db}$ \\
\hline PONTO 2 & $67.0 \mathrm{db}$ & $57.2 \mathrm{db}$ & $66.9 \mathrm{db}$ & $64.2 \mathrm{db}$ & $66.1 \mathrm{db}$ \\
\hline PONTO 3 & $60.2 \mathrm{db}$ & $61.5 \mathrm{db}$ & $66.1 \mathrm{db}$ & $65.1 \mathrm{db}$ & $60.9 \mathrm{db}$ \\
\hline PONTO 4 & $67.4 \mathrm{db}$ & $66.8 \mathrm{db}$ & $67.3 \mathrm{db}$ & $67.5 \mathrm{db}$ & $66.1 \mathrm{db}$ \\
\hline PONTO 5 & $70.2 \mathrm{db}$ & $70.4 \mathrm{db}$ & $72.8 \mathrm{db}$ & $75.6 \mathrm{db}$ & $71.2 \mathrm{db}$ \\
\hline
\end{tabular}

(b)

Fonte - Arquivo pessoal, 2015. 


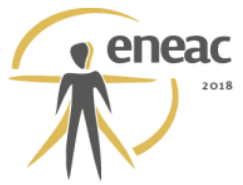

Ao representar na planta baixa (figuras $5 a$ e $5 b$ ), entende-se que a predominância da direção dos ventos é de sul/sudeste, com variação ao nordeste. Em relação ao ponto 1, o vento se direcionava, predominantemente, do sul/sudeste. Percebe-se também, que pela barreira encontrada no extremo sudeste do ateliê, esta corrente de vento é barrada, onde ocorre uma diminuição de sua intensidade neste local. Mesmo em pequena intensidade, sente-se uma corrente de vento vindoura do nordeste. Quando esses dados foram espacializados, viu-se que a maioria do vento percorre, em sua maioria, em direção aos lugares de entulhos, não favorecendo os usuários do ambiente, acomodados em lugares menos ventilados.

Figura 5 - Planta baixa com indicação das direções dos ventos que penetram o ambiente (a) e gráfico de predominância e velocidade dos ventos na cidade do Recife (b).

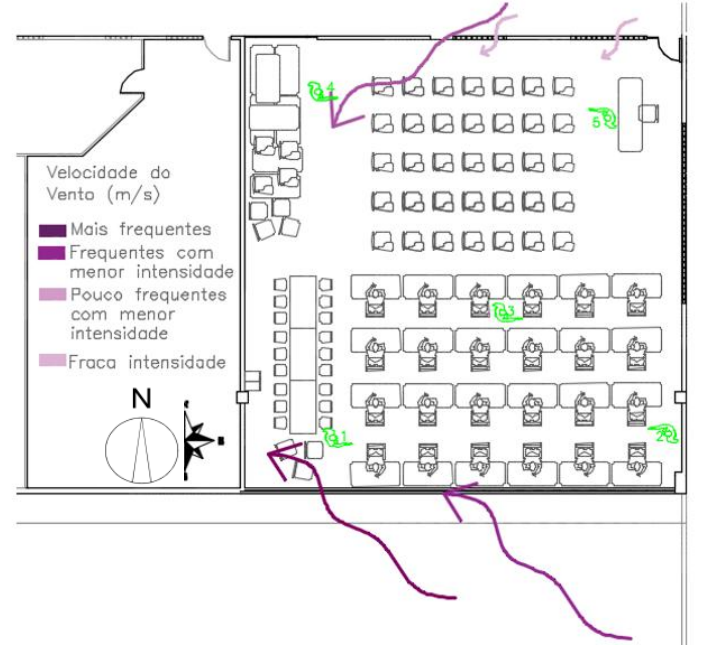

(a)

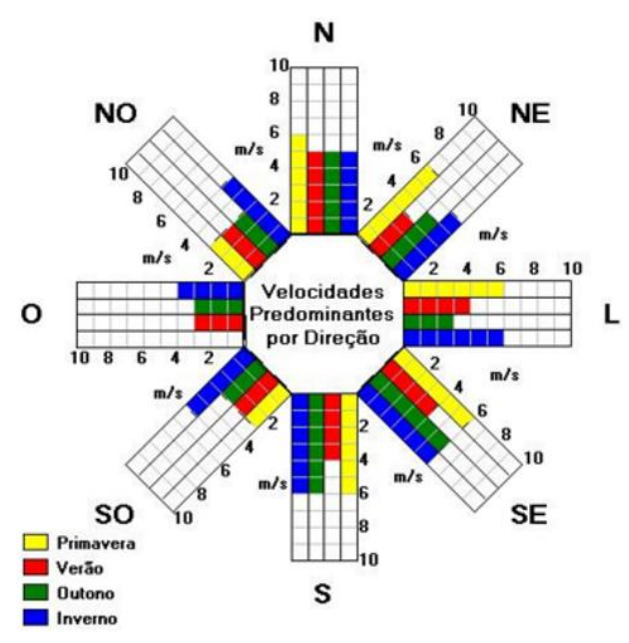

(b)

Fonte - Arquivo pessoal, 2015.

Ao analisar os resultados de acordo com a NR17, o ambiente avaliado apresentou valores acima do recomendado. Na norma regulamentadora propõe-se que este tipo de ambiente apresente a velocidade do ar que não ultrapasse o valor de $0,75 \mathrm{~m} / \mathrm{s}$. Assim, não proporcionando revés aos estudantes durante a execução de suas atividades acadêmicas.

Em relação à acústica do ambiente de estudo (tabela $2 b$ ), a partir das medições realizadas utilizaram-se os mesmos critérios das medições da velocidade do vento no ambiente, uma medição a cada minuto - têm-se algumas fontes de ruído a serem apresentadas. Ao fazer medições percebeu-se que existem, no ambiente, três fontes que promovem um alto nível de ruído, sendo: 1 . os pontos 1, 2 e 3 são marcados pela localização das pranchetas, onde, na maioria do tempo, os alunos permanecem, sendo assim, os usuários correspondem à primeira fonte que contribui com a incidência de ruído para no ambiente; 2 . o ponto 5 foi de extrema valia em sua localização, pois serviu para medir o quão o único ventilador em funcionamento no ambiente, encontrado imediatamente acima do ponto de medição, polui o ambiente, com seu ruído, assim, o estalido mecânico representa a segunda fonte de alto nível de ruído; 3. os transeuntes nos corredores e os usuários das salas vizinhas, que 


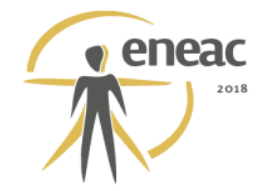

transmitem ao ambiente uma diversidade de ruídos, perceptível nos pontos 1,4 e 5 , representam a terceira fonte produtora de ruído, que se encontra no exterior do ambiente.

Com esta variação de 60 a 80db dentro do ambiente estudado (tabelas 1 e $2 b$ ), recorreu-se à NBR 10152/87. Nela, recomenda-se que ambientes como salas de aula e laboratórios tenham entre 40 à $50 \mathrm{db}$. Assim, comprova-se que o ambiente carece de um tratamento acústico, para assim, propor aos usuários um ambiente confortável, com menor incidência de ruídos.

No que se refere à luminosidade do ambiente, pode-se perceber, visualmente, um imenso contraste, comprovado ao fazer a medição com o luxímetro (tabela 1). Ao realizar a espacialização dos níveis de iluminamento (figura 6) - a partir da disposição do equipamento em cada ponto de medição, anteriormente destacados -, vê-se, espacializada em planta baixa, essa desconformidade lumínica: o extremo sul é aproximadamente $400 \%$ mais claro que o extremo norte da sala de aula.

De acordo com a NBR 5413/92 (iluminação de interiores), foi encontrado que salas de trabalhos manuais devem ter de 200 a 500 lux. Com isso, é percebido que a única área dentro desta recomendação é o extremo sul do ateliê - correspondente a dois dos cinco pontos de medição -, ou seja, a área que recebe toda a luz natural. Em virtude das medições terem sido feitas no turno da tarde, o sol encontrava-se em seguimento a oeste, assim, toma-se como justificativa este extremo sudoeste mais iluminado que o sudeste. As demais áreas do ambiente se encontram em estado precário no quesito de iluminação, o que proporciona aos usuários um nível muito alto de desconforto visual.

Figura 6 - Espacialização - medição de luminosidade.

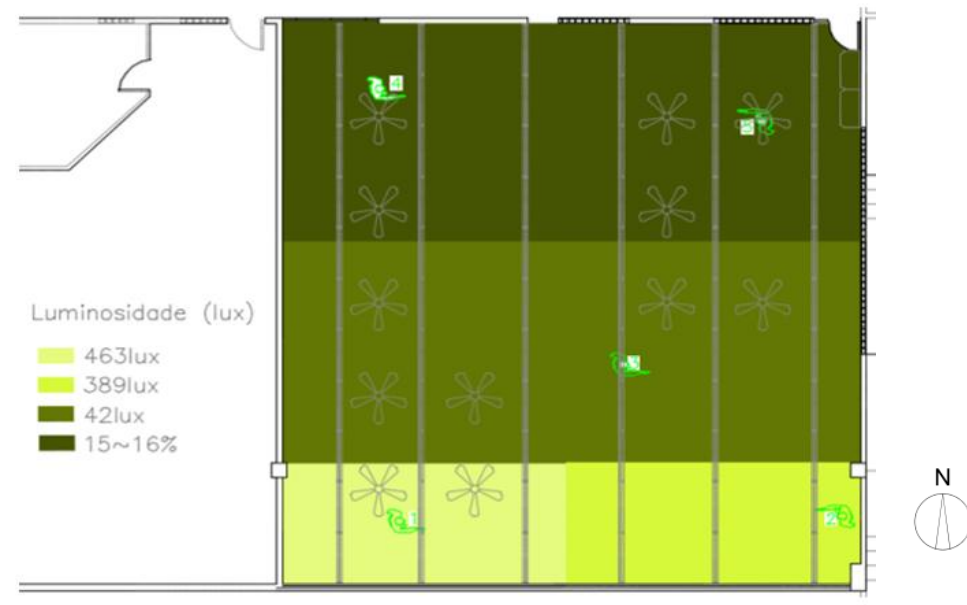

Fonte - Arquivo pessoal, 2015.

\subsection{Avaliação dos Fatores Antrópicos e Sociais}

Ao analisar tanto o espaço de trabalho do usuário permanente como o do transeunte, encontrou-se uma variação nos níveis de conforto espacial (figura 7). A partir do modelo antropométrico utilizado na análise, foi possível perceber os espaços de circulação que vão dos mais estreitos aos mais confortáveis. No modelo antropométrico do ateliê 4 , vê-se claramente o problema de locomoção causado pelo acúmulo de mobiliário nos corredores de pranchetas e zona teórica, os transeuntes, ao passar pelos estudantes que utilizam estes mobiliários, correm o risco de esbarrar, prejudicando o trabalho do colega de classe. 


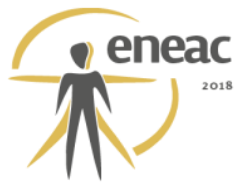

Também foi observado um fator de risco nos usuários que utilizam o lado oeste da grande mesa, eles necessitam ultrapassar obstáculos, os mobiliários empilhados e os alunos em cadeiras no extremo sudoeste, para chegar ao seu destino.

Figura 7 - Planta baixa antropométrica do ateliê 4.

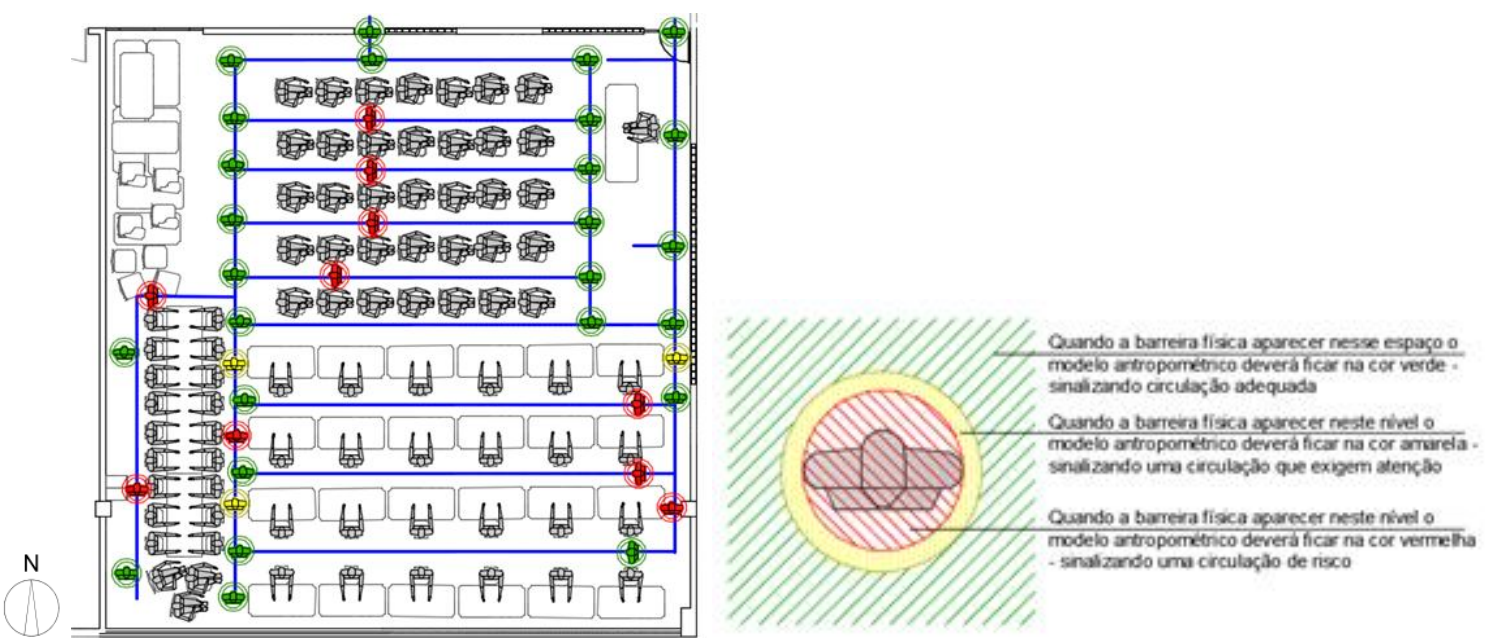

Fonte - Arquivo pessoal, 2015.

Encontram-se locais mais confortáveis nas áreas próximas aos entulhos e próximas ao quadro; ao começar o trabalho prático, os alunos sempre procuram tais lugares mais confortáveis para realizar os seus exercícios. A forma como o usuário se comporta no ambiente através do seu corpo nos faz refletir e compreender as suas sensações em relação ao ambiente e as necessidades para a melhoria do seu estado, até propor um lugar agradável. Através da análise dos usuários, chegamos a algumas conclusões quanto à relação do usuário com o espaço. Percebe-se que os alunos aplicam grande esforço em suas colunas (fotografia 1a), tal ato é promovido pela distância dos bancos à mesa, isto acontece, pois, ao aproximar o banco da mesa proporciona desconforto na região dos membros inferiores; logo, deve ser revisto o mobiliário, encontrando, assim, uma forma que traga a sensação de bem-estar ao usuário.

Fotografia 1 - Postura dos estudantes realizando suas atividades sentados e em pé.

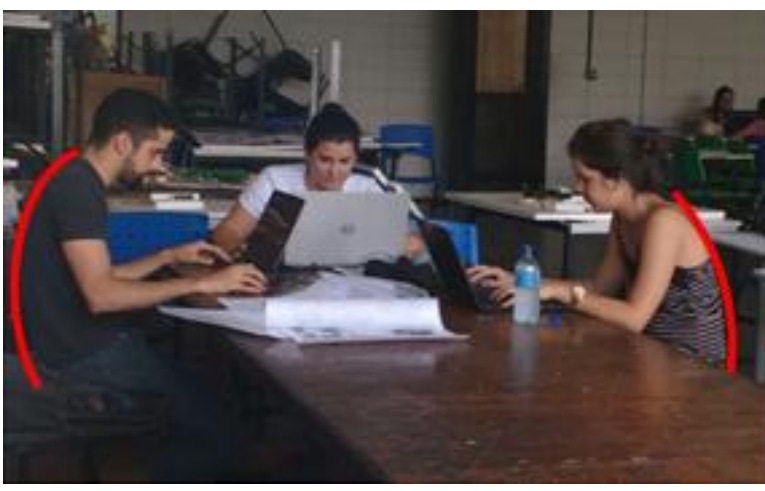

(a)

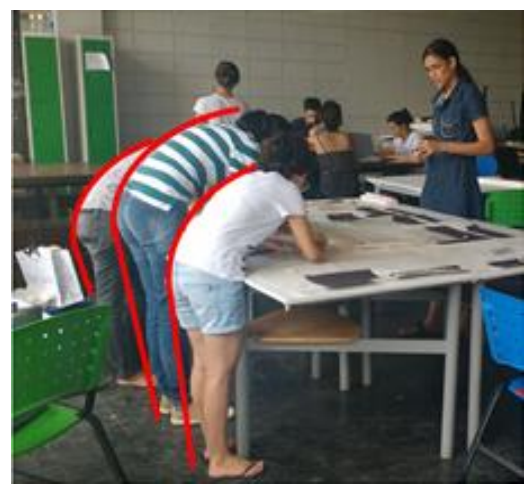

(b)

Fonte - Arquivo pessoal, 2015. 


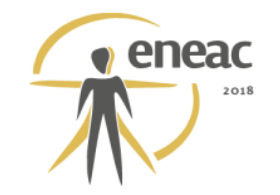

Há também a necessidade de posicionar-se em pé, em alguns casos, para a realização de atividades de maior porte (fotografia 1b). Logo, se deve analisar o dimensionamento de espaços de circulação, tanto para os transeuntes como para os usuários que se apropriam o mobiliário. Assim não causando comprometimento dos fluxos. Bem como, deve-se observar o tipo de mobiliário, que proporcione a realização de trabalhos em pé, sem causar prejuízos à postura dos usuários.

Como o objetivo do estudo focado na ergonomia é justamente entender a relação do homem com o seu ambiente de trabalho, é importante conhecer a percepção do usuário para com esse espaço. De acordo com Villarouco e Mont'Alvão (2011, p. 33), é necessário verificar a adequação ergonômica a partir desta relação, já que não se deve analisar apenas a ordem física do ambiente, mas também, as sensações psicológicas dos usuários, compreendendo de modo mais sensível a adequabilidade do ambiente de trabalho estudado.

Para isso, fez-se necessária a aplicação de um formulário (tabela 4) que abordou questões sobre conforto, acessibilidade, segurança e manutenção, além disso, o usuário era livre para opinar sobre os seus desejos com relação ao local. É importante destacar que as respostas do formulário reafirmaram os resultados apresentados anteriormente; o entulho, a temperatura e o ruído incomodam os usuários deste recinto, que almejam por melhores condições.

Tabela 4 - Formulário aplicado aos usuários.

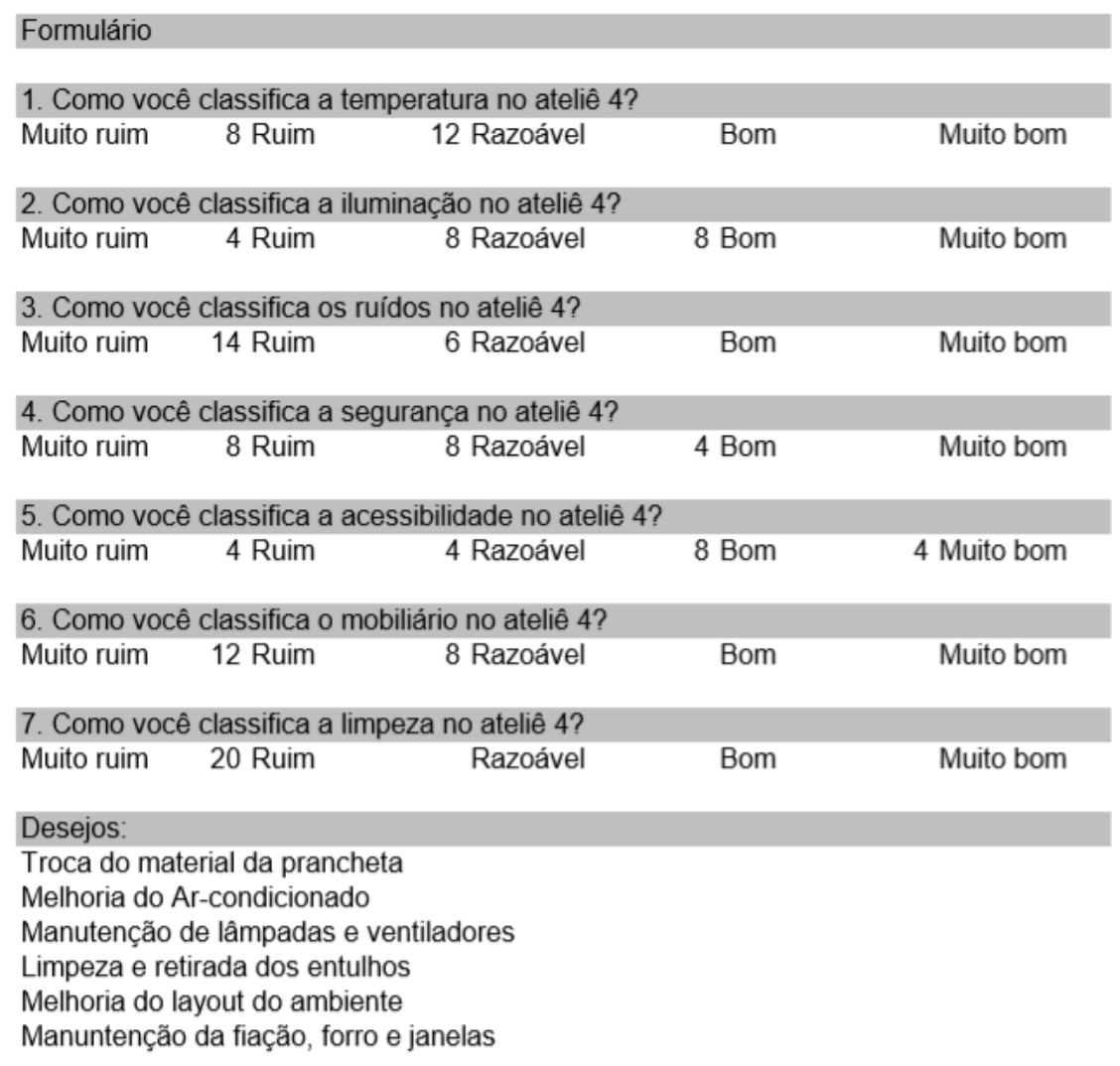

Fonte - Arquivo pessoal, 2015. 


\section{(x) $^{\text {enec }}$}

\section{A AVALIAÇÃO ERGONÔMICA COMO DIRETRIZ PARA A INTERVENÇÃO DO ESPAÇO}

Foi de perceptível importância a análise do ambiente em uso para se entender a fundo sua dinâmica no dia-a-dia e assim chegar no diagnóstico do ambiente. Há a existência de acessos que são bloqueados por mesas e cadeiras; em relação ao conforto, outro aspecto importante a ser avaliado, nota-se a falta de ventiladores e de lâmpadas em funcionamento; a falta de manutenção ocasionou o péssimo estado do forro, além disso, tem-se que alguns trechos encontram-se com a fiação elétrica exposta.

Com relação ao mobiliário, podem-se destacar as cadeiras, que, possuem encosto relativamente confortável e bom apoio para a coluna. A postura do punho e do cotovelo foi classificada como razoável, já que nem todas as cadeiras contam com apoio para os braços.

Após as medições, as observações diretas (análises visuais) e a aplicação de formulários chegou-se à conclusão de que o ateliê 4 é um espaço desconfortável, mal equipado e pouco conservado.

O importante a destacar é que a realização deste estudo permitiu um embasamento para futuras propostas de intervenções, a fim de tornar o ateliê 4 um espaço confortável e totalmente adequado a sua função. Ainda, de acordo com Villarouco e Mont'Alvão (2011, p.31) deve-se também considerar o estudo quanto à adequação de materiais, sejam revestimentos, acabamentos, cores ou texturas, analisando de modo técnico a sua contribuição para com o ambiente, tanto por meio físico, quanto por meio sensorial.

\section{REFERÊNCIAS}

ASSOCIAÇÃO BRASILEIRA DE NORMAS TÉCNICAS - ABNT. NBR9050 - Acessibilidade a edificações, mobiliário, espaços e equipamentos urbanos. Terceira Edição 11.09.2015.

ASSOCIAÇÃO BRASILEIRA DE NORMAS TÉCNICAS - ABNT. NBR5413 - Iluminância de Interiores. Maio de 1991.

CARLETTO, Ana Claudia; CAMBIAGHI, Silvana. Desenho Universal: um conceito para todos. (Realização Mara Gabrilli). São Paulo, 2008. (Página 12).

ERGONOMIA, NR17. Norma regulamentadora 17: Ergonomia. Redação dada pela Portaria MTPS n.ํ 3.751, de 23 de novembro de 1990. Atualização: Portaria SIT n.ำ13, de 21 de junho de 2007.

MONT'ALVÃO, Claudia; VILLAROUCO, Vilma. Um novo olhar para o projeto. Teresópolis - RJ: 2AB, 2011.

MORAES, Ana Maria de. Ergodesign do Ambiente Construído e Habitado. Ed. 1, Rio de Janeiro: iUsEr, 2004.

NBR NBR10152/87, ABNT. Níveis de ruído para conforto acústico. Junho de 1992.

VILLAROUCO, V. Construindo uma metodologia de avaliação ergonômica do ambiente - AVEA. Anais do 14을 Congresso Brasileiro de Ergonomia. Porto Seguro: ABERGO, 2008. 